\title{
A MODIFIED BRIGGS' RETRACTOR FOR DACRYOCYSTORHINOSTOMY
}

BY

\author{
H. B. Stallard
}

LONDON

IN the operation of dacryocystorhinostomy good exposure and facilities for manipulation may be effected by the use of a retractor which I have termed a modified Briggs' lacrymal retractor.

The modifications consist in a broad blade-like termination of the shank on the temporal side. This shank is armed with three

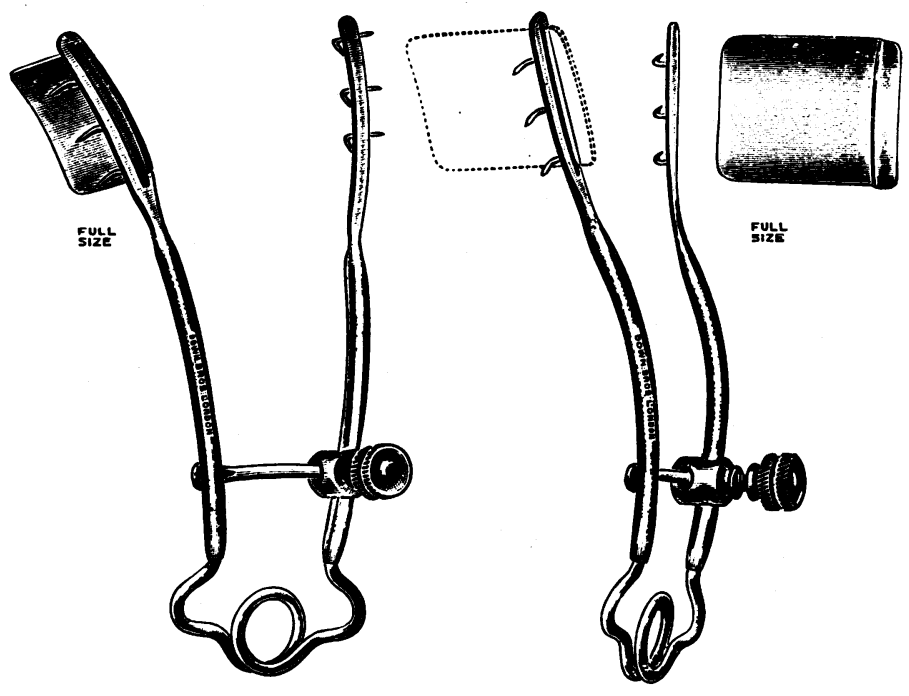

blunt curved claws for insertion into the soft tissues and in addition has a slot $16 \mathrm{~mm}$. long by $\frac{2}{3} \mathrm{~mm}$. wide for the purpose of inserting a curved metal guard $16 \mathrm{~mm}$. long by $18 \mathrm{~mm}$. deep.

The guard is inserted through the slot at a stage in the operation when the sac has been dissected away from the lacrymal fossa and is drawn temporally, the guard being placed between the sac and the lacrymal fossa. By opening the retractor widely the lacrymal sac and orbital tissues are displaced to the temporal side and protected from injury during the removal of the oval window of bone from the lacrymal fossa. This instrument gives a good exposure, is neater and more exact than any hand retractor and also allows the assistant to have another hand free.

The instrument has been made for me by Down Brothers. 